\title{
Mediastinoscopy-assisted minimally invasive closure of a bronchopleural fistula: A new technique to manage an old problem
}

\author{
Shawn S. Groth, MD, Jonathan D'Cunha, MD, PhD, Natasha M. Rueth, MD, Rafael S. Andrade, MD, and \\ Michael A. Maddaus, MD, Minneapolis, Minn
}

Bronchopleural fistulas (BPFs) that develop after pneumonectomy are associated with significant morbidity, can be challenging to manage, and are fraught with high recurrence rates after attempted closure. We herein describe a novel, minimally invasive technique to close a BPF that developed in one of our patients after a pneumonectomy for lung cancer.

\section{CLINICAL SUMMARY}

Our patient is a 62-year-old man who initially underwent a right upper lobectomy and adjuvant radiation therapy (because the tumor invaded the visceral pleura) for stage $\mathrm{Ib}$ non-small-cell lung cancer at an outside institution. Two years later, he experienced a hilar recurrence and underwent a completion right pneumonectomy. The patient was left with a long bronchial stump. He was subsequently referred to our institution when he experienced a BPF with an associated empyema (Figure 1, $A$ ).

From the Department of Surgery, Division of General Thoracic and Foregut Surgery, University of Minnesota, Minneapolis, Minn.

Disclosures: None.

Received for publication April 24, 2009; revisions received July 15, 2009; accepted for publication Aug 2, 2009; available ahead of print Oct 26, 2009.

Address for reprints: Michael A. Maddaus, MD, University of Minnesota Department of Surgery, Section of Thoracic and Foregut Surgery, MMC 207, 420 Delaware St SE, Minneapolis, MN 55455 (E-mail: madda001@umn.edu).

J Thorac Cardiovasc Surg 2010;140:244-5

$0022-5223 / \$ 36.00$

Copyright $(2) 2010$ by The American Association for Thoracic Surgery doi:10.1016/j.jtcvs.2009.08.015
After draining his empyema and constructing an Eloesser flap, we attempted to close his BPF with a muscle flap. Unfortunately, sequential serratus anterior and latissimus dorsi flaps failed to seal the BPF, resulting in recurrent pulmonary and pleural space infections and a poor quality of life. Because of severe mediastinal fibrosis (from radiation therapy, previous attempts at BPF closure, and recurrent infections), his bronchial stump could not be readily accessed for attempted closure by means of repeat thoracotomy. Consequently, we developed a new method in the cadaver laboratory for closure of a postpneumonectomy BPF using a mediastinoscopyassisted minimally invasive cervical approach to the right mainstem bronchus and used this approach to close our patient's BPF.

The patient was placed supine on the operating room table. After induction of general anesthesia, he was intubated with a single-lumen $8-\mathrm{mm}$ endotracheal tube. A 2-cm transverse skin incision was made $1 \mathrm{~cm}$ above the suprasternal notch, which is similar to an incision that would be used for standard cervical mediastinoscopy (Figure 2, A). By using blunt finger dissection, the dissection was carried down in the pretracheal plane. After digitally elevating the skin and subcutaneous tissues away from the mediastinum, bilateral 1-cm supraclavicular skin incisions were made just medial to the insertion site of each sternocleidomastoid (Figure 2, A). This provided 3 access incisions to enter the mediastinum in the pretracheal plane.

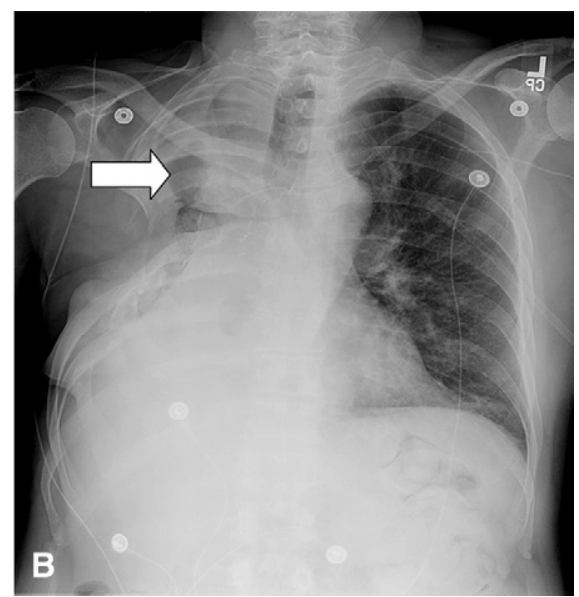

FIGURE 1. A, Preoperative chest radiograph (showing the long bronchial stump [black arrow]) and its open communication with the empyema cavity and thoracostomy window (white arrow). B, Postoperative chest radiograph showing closure of the bronchial stump and resolution of empyema. A small residual thoracostomy cavity remains (white arrow). 
By using the rigid suction normally used with a mediastinoscope, the anterior distal right side of the trachea, the tracheobronchial angle, and the anterior, medial, and lateral aspects of the right mainstem bronchial stump were dissected free from the surrounding tissues. The mediastinoscope was inserted into the right sternocleidomastoid incision, and the tip of the mediastinoscope was insinuated posterior to the right mainstem bronchial stump, allowing us to safely complete the posterior dissection of the right mainstem bronchus using a combination of blunt dissection (with the rigid suction) and laparoscopic hook electrocautery.

The mediastinoscope was placed in the middle (suprasternal notch) incision, and a 12-mm port was placed through the other 2 incisions, one for a 10-mm 30-degree camera and one for a stapler. A 4.8-mm articulating Endo GIA stapler (Covidien, Mansfield, Mass) was advanced through the right-sided port and secured around the right mainstem bronchus. Before firing the stapler, flexible bronchoscopy and esophagoscopy were performed to ensure there was no impingement on his airway or esophagus (Figure 2, B). As demonstrated on his postoperative chest radiograph, our minimally invasive technique successfully closed his BPF and led to resolution of his empyema (Figure 1,B).

There were no perioperative complications. Operating room time was 166 minutes. Estimated blood loss was $100 \mathrm{~mL}$. After an unremarkable convalescence, he was discharged home on the third postoperative day. At 2 years of follow-up, his empyema had resolved, his thoracostomy wound had healed by means of secondary intention, and his BPF had not recurred. Unfortunately, the patient succumbed to metastatic disease $2 \frac{1}{2}$ years after his BPF was closed.

\section{DISCUSSION}

The incidence of BPFs is $1.5 \%$ to $15 \%$ after pneumonectomy, depending on surgeon experience, use of neoadjuvant chemoradiation therapy, right-sided pneumonectomy, length of the bronchial stump, type of bronchial closure, predicted postoperative pulmonary function, and prolonged mechanical ventilation. ${ }^{1-3}$ Our patient had several of these risk factors, including (1) neoadjuvant radiation therapy, (2) a right-sided pneumonectomy, and (3) a long bronchial stump.

A number of bronchoscopic and surgical treatment strategies for BPFs have been described. ${ }^{3,4}$ The choice of treatment should be tailored to the patient's functional status,
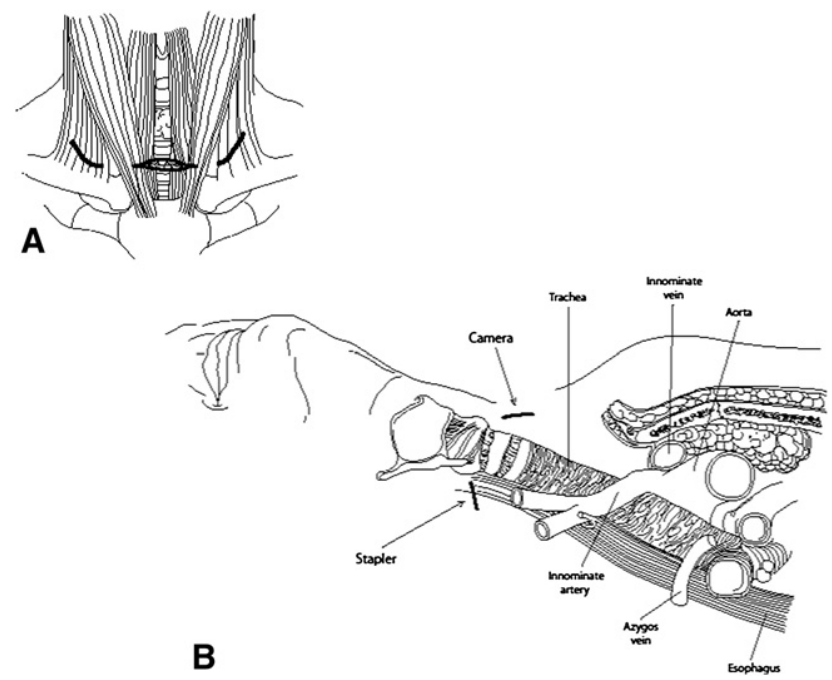

FIGURE 2. Skin incisions for mediastinoscopic access (A) and trocar placement for mediastinoscopy-assisted stapling of the right mainstem bronchus (B). Artwork by Lisa D'Cunha.

BPF size, and the expertise of the physician. Larger BPFs that develop after pneumonectomy often require a thoracotomy, decortication, drainage of any associated empyema, and bronchial stump reinforcement (with staples, suture, or soft tissue); the success rate for such strategies can exceed $80 \% .^{3}$

For our patient, severe mediastinal fibrosis and failure of several conventional modalities prompted us to devise a novel treatment strategy. We believe that this safe, minimally invasive technique can achieve excellent long-term results and might be especially well suited for other patients (like ours) with a long bronchial stump and severe mediastinal fibrosis.

\section{References}

1. Deschamps C, Bernard A, Nichols FC 3rd, Allen MS, Miller DL, Trastek VF, et al. Empyema and bronchopleural fistula after pneumonectomy: factors affecting incidence. Ann Thorac Surg. 2001;72:243-8.

2. al-Kattan K, Cattelani L, Goldstraw P. Bronchopleural fistula after pneumonectomy for lung cancer. Eur J Cardiothorac Surg. 1995;9:479-82.

3. Deschamps C, Allen MS, Miller DL, Nichols FC 3rd, Pairolero PC. Management of postpneumonectomy empyema and bronchopleural fistula. Semin Thorac Cardiovasc Surg. 2001;13:13-9.

4. Lois M, Noppen M. Bronchopleural fistulas: an overview of the problem with special focus on endoscopic management. Chest. 2005;128:3955-65. 